\title{
Eddy Current Speed Sensor with Magnetic Shielding
}

\author{
Mehran Mirzaei, Pavel Ripka, Andrey Chirtsov, and Vaclav Grim \\ Faculty of Electrical Engineering, Czech Technical University, Prague 16627, Czech Republic \\ (e-mails: mirzameh@ fel.cvut.cz, ripka@ fel.cvut.cz)
}

\begin{abstract}
This paper presents the design and analysis of a new eddy current speed sensor with ferromagnetic shielding. Aluminum and solid iron are considered for the moving part. One excitation coil and two antiserially connected pick u p coil s are shielded by a thin steel lamination. 3D time st epping fin ite element analysis is used to analyze the sensor performance wi th different magnetic materials and compared with experimen tal results. The compactness, simplicity and excellent linearit $y$ with different magnetic materials for the moving part show uniqueness of the proposed speed sensor. The shielding increases sensitivity and reduces the influence of close ferromagnetic objects and interferences on the sensor performance.
\end{abstract}

Keywords-Eddy current speed sensor, aluminum, iron, shielding, magnetic pe rmeability and finite element method.

\section{INTRODUCTION}

Speed sensors are vital parts of linear and rotating machines for control and protection purposes [1]-[3]. Contactless magnetic speed sensors are resistant against dust and oil, which brings them advantage over optical sensors [4]. The most popular sensor type is based on reluctance variation. Eddy current speed sensors work for all conduc ting moving bodies including those with smooth surface. They have simple cons truction and present favorable solution especially at high speeds. Longitudinal and perpend icular configurations of eddy current speed sensors and speed effects utilizations were presented in [5]-[11]. The presented models in [5] - [11] had only nonmagnetic aluminummoving part, which is simpler for analys is butnot practical for ind us try in comparison with solid iron moving part. The authors analyzed and tested similar eddy current speed sensors for solid iron rod line ar [12] and rotational configuration [13] without magnetic yoke and shield. These sensors suffered from sensitivity to magnetic interference and also to the presence of ferromagnetic materials from their vicinity. The magnetic shielding and magnetic yoke can increase the sensitivity of eddy current speed sensors as it provides low magnetic reluctance for the magnetic flux.

In this paper, a linear eddy current speed sensor with magnetic yoke and shielding using $0.5 \mathrm{~mm}$ silicon steel lamination is presented. Aluminum and solid iron moving bodies are both used in the finite element method (FEM) modeling and measurements. The effects of magnetic materials of the shielding are also investigated. Different excitation frequencies and speeds are considered in the measurements and analysis to obtain best sensor output linearity and sensitivity.

\section{EDDY CURRENT SPEED SENSOR}

\section{A. Model}

Table I and Fig. 1 present the eddy current speed sensor model and parameters. Parameter, $V$ is the speed in Fig. 1.

Table I

Eddy current speed sensor parameters

\begin{tabular}{|c|c|c|}
\hline \multicolumn{2}{|r|}{ PARAMETERS } & Values \\
\hline$I$ & excitation coil current amplitude & $166 \mathrm{~mA}$ \\
\hline$N$ & number of turn in all coils & 100 \\
\hline$L$ & moving part width & $100 \mathrm{~mm}$ \\
\hline$h_{\mathrm{m}}$ & moving part thickness & $5.0 \mathrm{~mm}$ \\
\hline$h_{\mathrm{c}}$ & coils thickness & $4.7 \mathrm{~mm}$ \\
\hline$w_{\mathrm{c}, \mathrm{o}}$ & outer coil width & $29.0 \mathrm{~mm}$ \\
\hline$w_{\mathrm{c}, \mathrm{i}}$ & inner coil width & $25.0 \mathrm{~mm}$ \\
\hline$w_{\mathrm{s}}$ & ferromagnetic shield width & $30 \mathrm{~mm}$ \\
\hline$l_{\mathrm{s}}$ & ferromagnetic shield length & $90 \mathrm{~mm}$ \\
\hline$\overline{\sigma_{\mathrm{al}}}$ & $\begin{array}{c}\text { moving part aluminum conductivity at room } \\
\text { temperature }\end{array}$ & $\begin{array}{c}33.5 \\
\mathrm{MS} / \mathrm{m}\end{array}$ \\
\hline$\overline{\sigma_{\mathrm{i}}}$ & $\begin{array}{c}\text { moving part solid iron conductivity at room } \\
\text { temperature }\end{array}$ & $6.0 \mathrm{MS} / \mathrm{m}$ \\
\hline$\overline{\mu_{\mathrm{ri}}}$ & $\begin{array}{l}\text { relative magnetic permeability of moving part solid } \\
\text { iron }\end{array}$ & 100 \\
\hline$\sigma_{\mathrm{s}}$ & silicon steel shield conductivity & $3.1 \mathrm{MS} / \mathrm{m}$ \\
\hline$\mu_{\mathrm{rs}}$ & $\begin{array}{l}\text { relative magnetic permeability of silicon steel } \\
\text { shield }\end{array}$ & 1000 \\
\hline
\end{tabular}

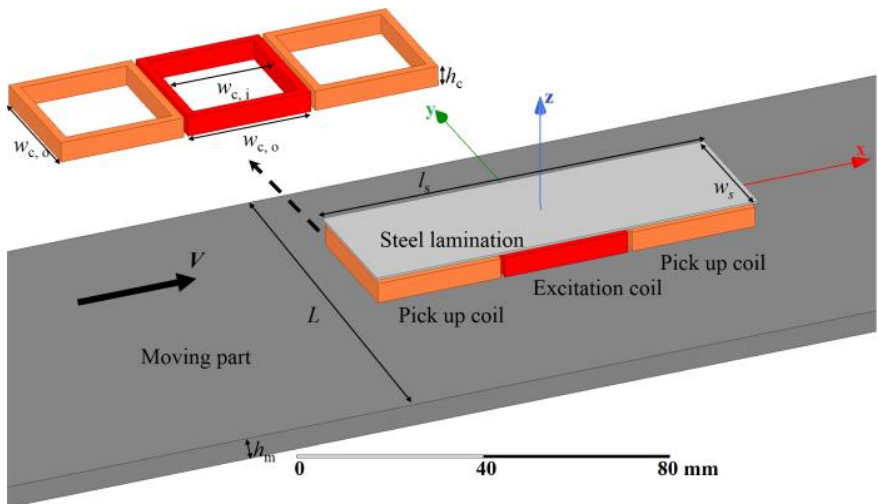

Fig. 1. Eddy current speed sensor with steel lamination for shielding 
Final version at JMMM 502, 15 May 2020, paper\# 166568 https://doi.org/10.1109/JSEN.2020.3000442
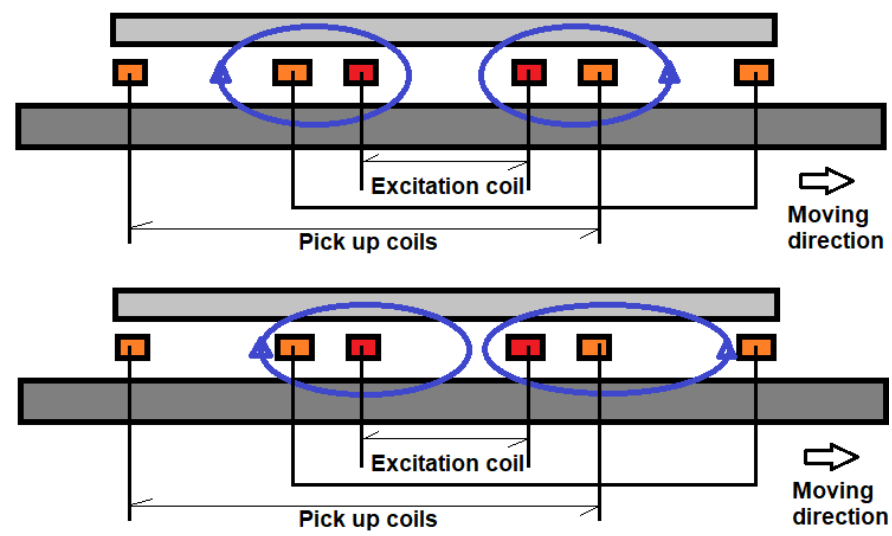

Fig. 2. 2D schematic models of eddy current speed sensor and moving part with single excitation coil and antiserially connected pick up coils - at zero speed (up) and nonzero speed (bottom)

\section{B. Operation Theory}

Two pick up coils (Fig. 1 and Fig. 2) are. Ideally induced voltage and net flux in the antiserially pick up coils are zero at zero speed because left and right side coils have same flux linkage with the excitation coil. The net total flux of antiserially connected pick up coils is nonzero at nonzero speed because pick up coils sense different flux linkages due to the induced eddy currents as shown in Fig. 2. The flux linkages of pick up coils are affected unevenly by motion component of induced eddy current [5], [14]. As speed increases, the differencebetween induced voltages of left and right side coils increases, which is utilized for the speed sensing for solid conductive moving objects.

\section{Speed Sensor Measurements}

\section{A. Experimental setup}

Experimental set up and measurement devices are shown in Fig. 3. A rotating disk (aluminum and iron) with thickness $5 \mathrm{~mm}$ is considered as moving part. The disk rotates between $-500 \mathrm{rpm}$ up to $+500 \mathrm{rpm}$ and center of eddy current speed sensor is located $22.5 \mathrm{~cm}$ distance from disk center. The dimensions of eddy current speed sensor are reasonably small in comparis on with rotating disk therefore it can be as sumed that eddy current speed sensor sense linear speed rela tive to the rotating disk. The electrical conductivities of iron and aluminum disk were measured and mentioned in Table I at room temperature. Lock-in amplifier is used for precise measurements of pick up coils voltage. A signal generator with internal resistance $50 \Omega$ is connected to the excitation coil.

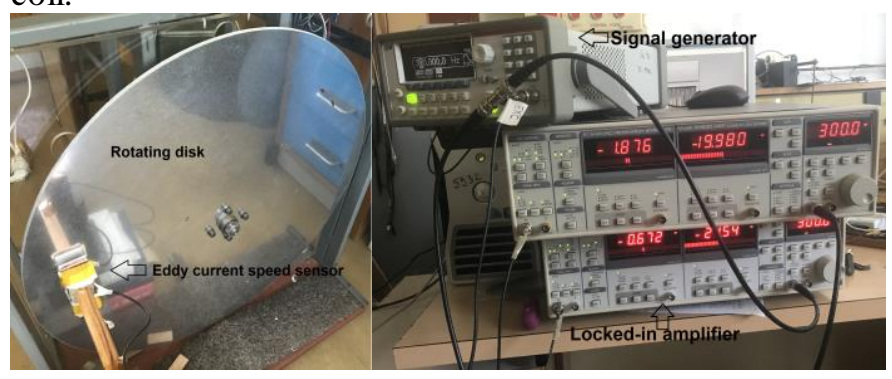

Fig. 3. Experimental set up - rotating disk (aluminum and solid iron) as moving part and eddy current based speed sensor (left) and signal generator and locked-in amplifier (right)

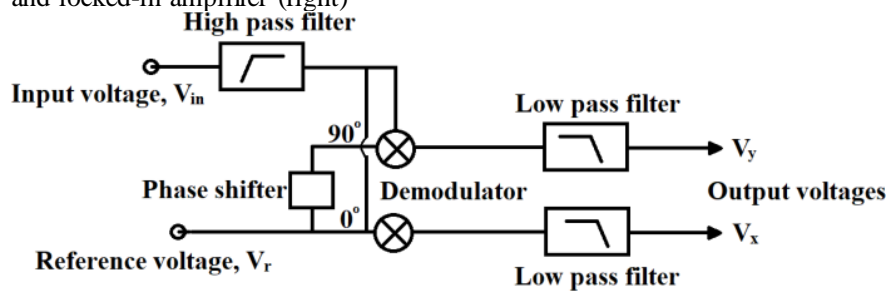

Fig. 4. Schematic block diagram to demonstrate the possible electronics diagram to process speed sensor output signal

Fig. 4 shows schematic block diagram, which can be considered for possible electronic design for the sensor.

\section{B. Speed sensor results}

Fig. 5 and Fig. 6 present measured absolute value of measured voltage, $V_{\mathrm{a}}$ of pick up coils:

$V_{\mathrm{a}}=\sqrt{V_{r}^{2}+V_{i}^{2}}$

where, $V_{\mathrm{r}}$ and $V_{\mathrm{i}}$ are real component and imaginary component of induced voltage in the antiserially connected pick up coils relative to the excitation coil current as reference signal. The polarity of absolute value of voltage is calculated using phase shift relative to the excitation coil current.

Pick up induced voltages for the iron rotating disk incre ase with increasing excitation coil frequency, which is different to the aluminium rotating disk. Linearity of induced voltage versus linear speed for iron rotating rod is the be st at $300 \mathrm{~Hz}$ and it is the best between $120 \mathrm{~Hz}$ and $180 \mathrm{~Hz}$ for aluminium rotating disk. The gap between coils of eddy current speed sensor and rotating disk is about $6.25 \mathrm{~mm}$, which is suffic ien $\mathrm{t}$ reasonable value for many industrial applications. High linearity of induced voltage curve versus speed makes the proposed sensor to be suitable device for speed meas urement. The real component and imaginary component of induced voltages show differenttendency vers us speed (Fig. 7-Fig.8). 
Final version at JMMM 502, 15 May 2020, paper\# 166568 https://doi.org/10.1109/JSEN.2020.3000442

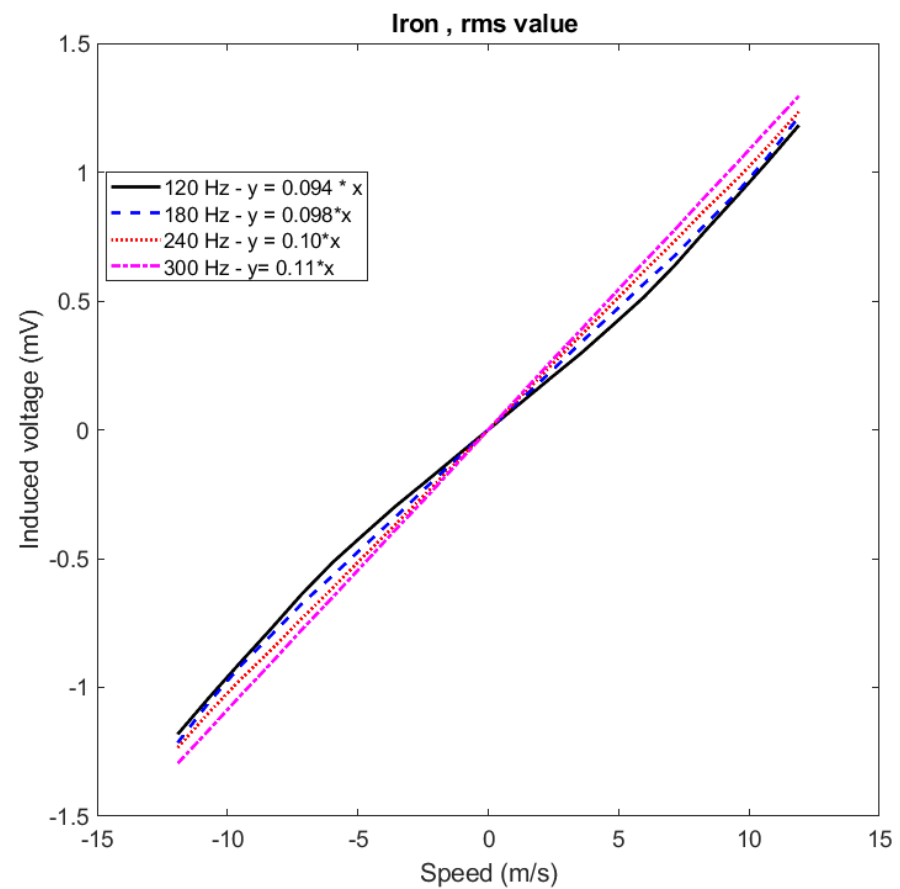

Fig. 5. Measured voltage of pick up coils for iron rotating disk at different frequencies - absolute value

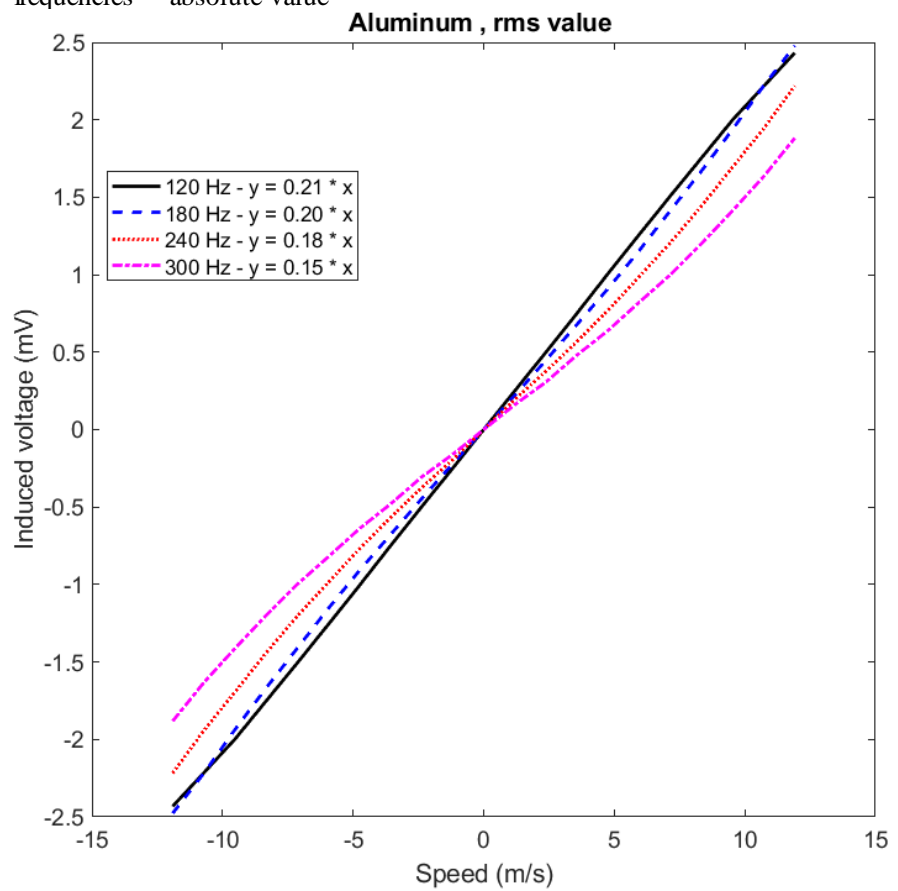

Fig. 6. Measured voltage of pick up coils for aluminum rotating disk at different frequencies - absolute value

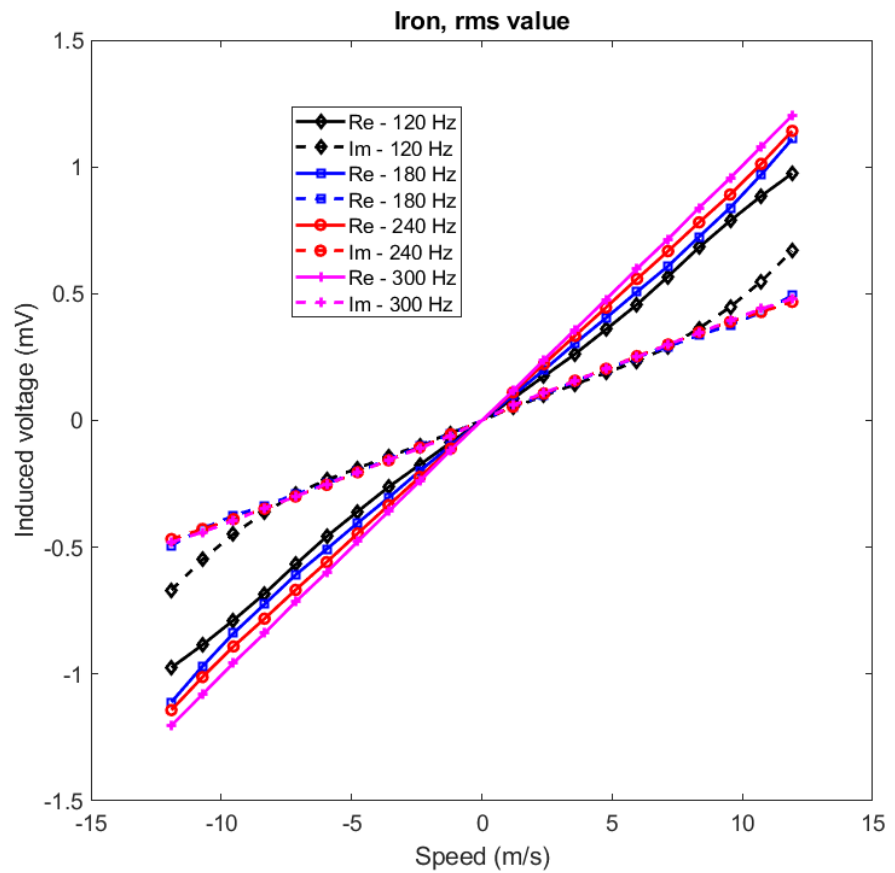

Fig. 7. Measured real component (Re) and imaginary component (Im) of induced voltage of pick up coils for iron rotating disk

Real component of induced voltage is more linear versus speed for all frequencies in comparison with imaginary component and its linearity is less dependent on the excitation frequency. Real component of induced voltage is proportional to the los ses component in the rotating disk, which could be more reluctant to the speed sensor lift off.

It is shown that eddy current speed sensor sensitivity is highly dependent on the moving part material properties. Conductivity of aluminumand iron moving part and relative permeability of iron moving part could change ed dy current speed sensor outputs [13]. Compens ating moving part material properties on the eddy current speed sensor output is a challenging is sue and it must be addressed.

The root mean square error (RMSE) for linearity in percentage value as an indicator [15] for representation of fitness of measured values to the linear curve fit is calcu lated about $0.26 \%$ for iron rotating disk at $300 \mathrm{~Hz}$. Fig. 9 shows the error in percent of full range as an alternative approach for linearity error evaluation of speed sensor, which shows imaginary component of induced voltage is more line ar than real component of induced voltage. 
Final version at JMMM 502, 15 May 2020, paper\# 166568 https://doi.org/10.1109/JSEN.2020.3000442

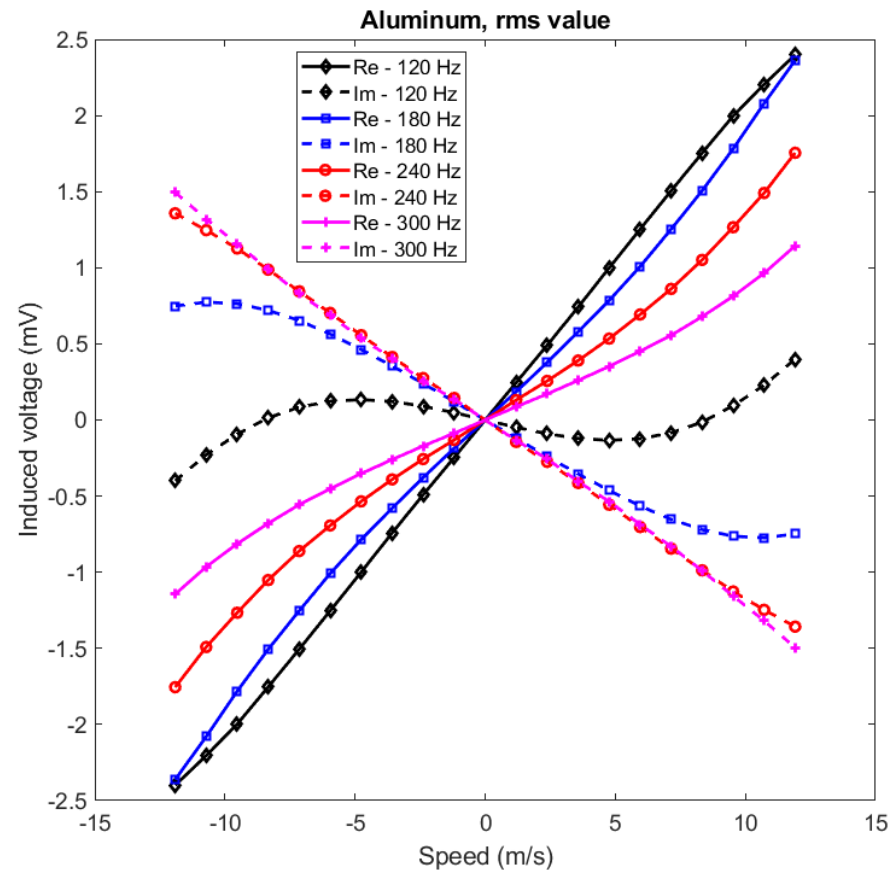

Fig. 8. Measured real component (Re) and imaginary component (Im) of induced voltage of pick up coils for aluminium rotating disk

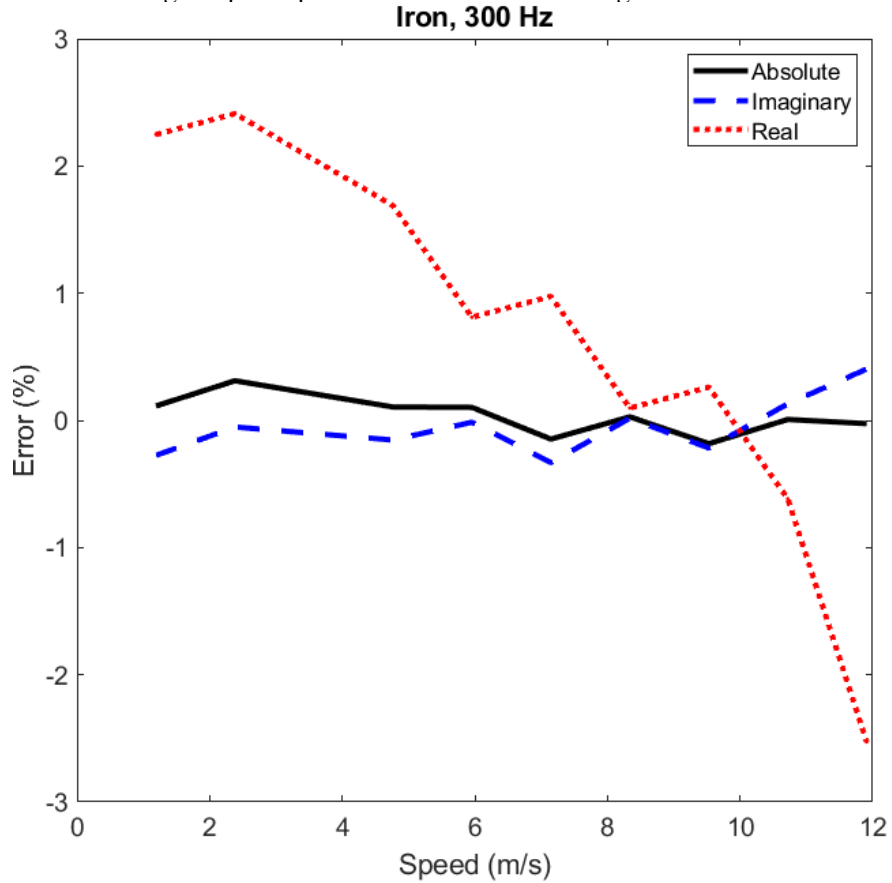

Fig. 9. Linearity error versus speed for absolute, imaginary and real components of induced voltages

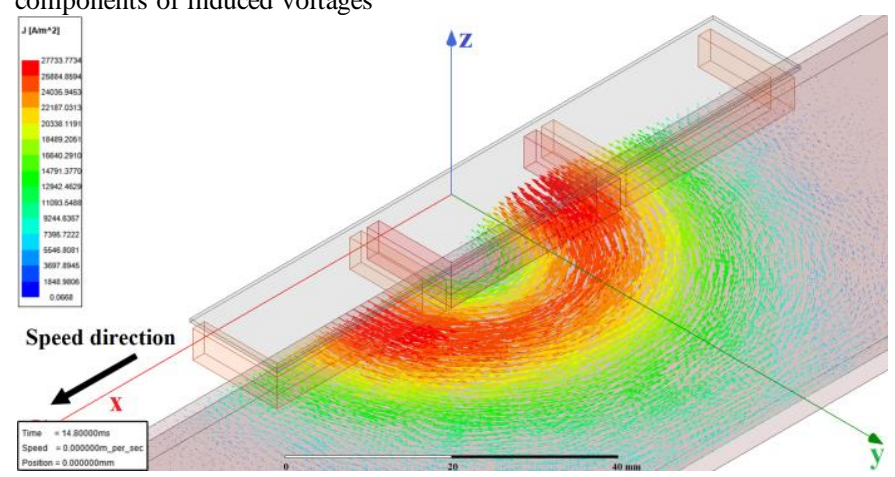

Fig. 10. Eddy current distribution in the aluminium moving part at zero speed

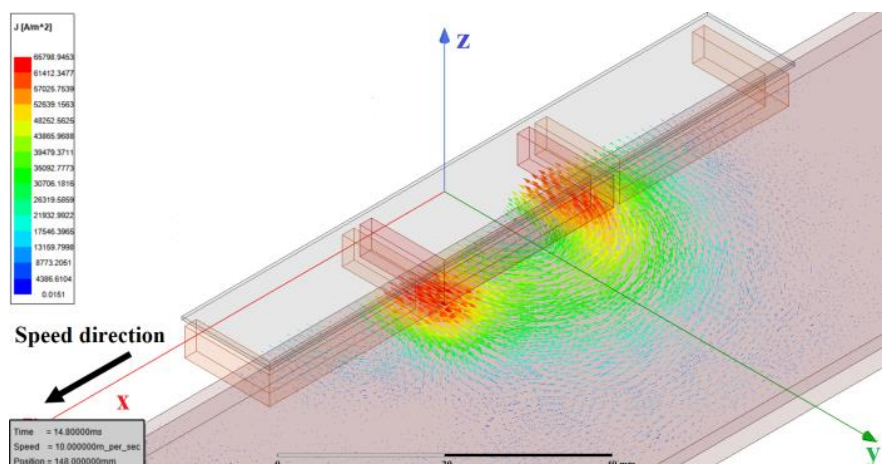

Fig. 11. Eddy current distribution in the aluminium moving part at $10 \mathrm{~m} / \mathrm{s}$

\section{3D FEM ANALYSIS}

The performance of eddy current speed sensor is an alyzed using time stepping 3D FEM tool [16]. The motion of moving part is considered at different speeds. Sliding mesh method is used in the FEM tool to model motion of moving part. The eddy current effects are taken into count in the shielding too as well as conductive moving part. In order to model accurately skin effects in the moving part and shielding, the mesh sizes are adjusted accordingly. Second order elements are utilized in the FEM tool, which high accuracy analysis could be achieved.

Only half of model is analyzed because of symmetry to save simulation time. Eddy current distribution in the aluminum moving part at zero speed and $10 \mathrm{~m} / \mathrm{s}$ are shown in the Fig. 10 and Fig. 11. Eddy current distribution changes from symmetric form (Fig. 10) to asymmetric form (Fig. 11) due to the speed effect, which causes different induced voltage in the left and right side pick up coils.

\section{A. Comparison between Experiments and FEM}

Table II presents comparis on between 3D FEM analysis and measurements at $2 \mathrm{~m} / \mathrm{s}, 5 \mathrm{~m} / \mathrm{s}$ and $10 \mathrm{~m} / \mathrm{s}$ for aluminum and iron rotating disks. 3D FEM results coincide very well with measurements, which show accuracy of 3D FEM and its suitability for further steps, for example, eddy cu rrent s peed sensor optimization and material effects evaluations.

Fig. 12 shows comparis on between experimental and 3D FEM results versus time for rotating iron disk at $10 \mathrm{~m} / \mathrm{s}$.

Linear modelis used for the simulation as sensor size and dimensions are very small in comparis on with rotating disk. It is convenient to use disk orcylinder as a fine app ro ximation for linear motion [17]-[20]. 
Final version at JMMM 502, 15 May 2020, paper\# 166568 https://doi.org/10.1109/JSEN.2020.3000442

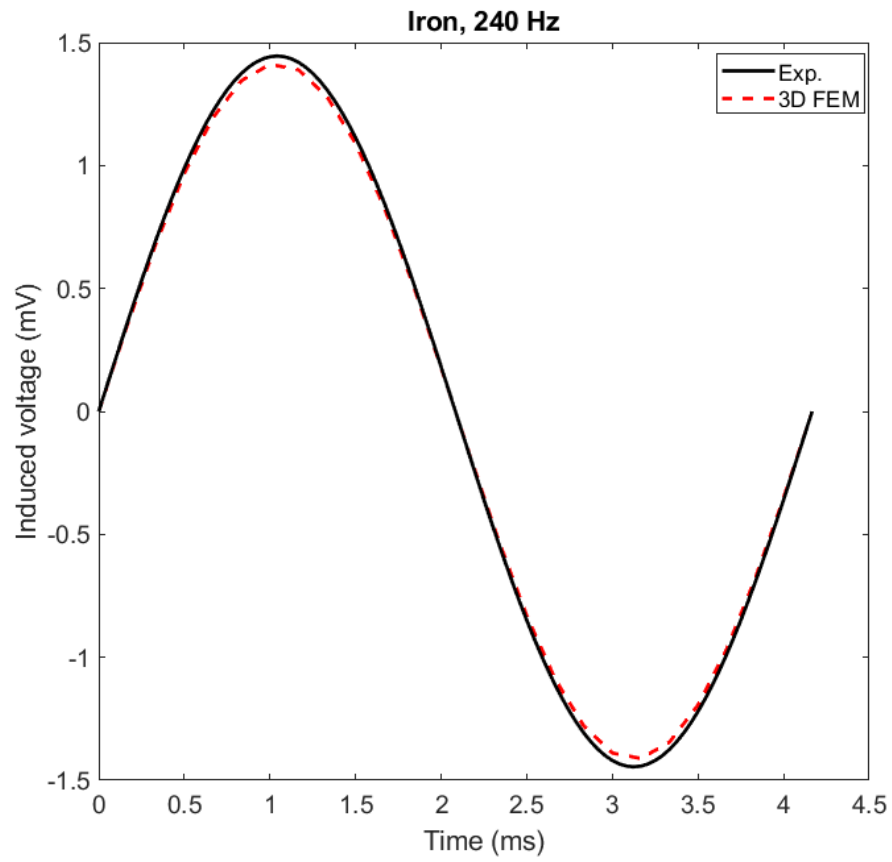

Fig. 12. Comparison between experimental and 3D FEM curves versus time at $10 \mathrm{~m} / \mathrm{s}$

Table II

Comparison between experimental results and FEM for induced voltage $(\mathrm{mV})$

\begin{tabular}{|c|c|c|c|}
\hline & $2 \mathrm{~m} / \mathrm{s}$ & $5 \mathrm{~m} / \mathrm{s}$ & $10 \mathrm{~m} / \mathrm{s}$ \\
& Exp./ & Exp./ & Exp./ \\
& FEM & FEM & FEM \\
\hline Aluminum & $0.42 /$ & $1.057 /$ & $2.085 /$ \\
$120 \mathrm{~Hz}$ & 0.429 & 1.075 & 2.185 \\
\hline Aluminum & $0.318 /$ & $0.815 /$ & $1.793 /$ \\
$240 \mathrm{~Hz}$ & 0.294 & 0.845 & 1.889 \\
\hline Iron & $0.168 /$ & $0.427 /$ & $0.959 /$ \\
$120 \mathrm{~Hz}$ & 0.17 & 0.446 & 0.99 \\
\hline Iron & $0.207 /$ & $0.514 /$ & $1.022 /$ \\
$240 \mathrm{~Hz}$ & 0.212 & 0.513 & 1.0 \\
\hline
\end{tabular}

B. Ferromagnetic Materials Evaluation of Magnetic Shield and Moving Part

Table III presents effect of relative magnetic permeability of iron moving part on the sensor output. With increasing permeability the sensitivity is decreasing due to the dec re ase of penetration depth. Relative magnetic permeability varies for different steels and irons [21]-[22].

Effect of magnetic shielding is evaluated in the Table IV. First case is silicon steel with $0.5 \mathrm{~mm}$ thickness and es timated relative magnetic permeability 1000 . The relative magnetic permeability in the second case is changed to 100 , which induced voltage decreases considerably because of higher reluctance in the magnetic fluxpath. Third case is Ferrite core with $5 \mathrm{~mm}$ thickness and relative magnetic permeability 2000 for magnetic shielding, which induced voltage increases. Howevereddy current speed sensor becomes thicker and les s compact.

Table III

FEM results of induced voltage $(\mathrm{mV})$ for different moving part permeability rms value

\begin{tabular}{|c|c|c|c|}
\hline $10 \mathrm{~m} / \mathrm{s}$ & $\mu_{\mathrm{ri}}=75$ & $\mu_{\mathrm{ri}}=100$ & $\mu_{\mathrm{ri}}=125$ \\
\hline $120 \mathrm{~Hz}$ & 1.12 & 0.99 & 0.88 \\
\hline
\end{tabular}

\begin{tabular}{|c|c|c|c|}
\hline $240 \mathrm{~Hz}$ & 1.15 & 1.0 & 0.90 \\
\hline \multicolumn{3}{|c|}{ Table IV } \\
\hline
\end{tabular}

FEM results of induced voltage $(\mathrm{mV})$ for different magnetic shield materials -

\begin{tabular}{|c|c|c|c|}
\hline \multicolumn{4}{|c|}{ rms value } \\
\hline $10 \mathrm{~m} / \mathrm{s}$ & $\begin{array}{c}1-\mu_{\mathrm{rs}}=1000 \\
\sigma_{\mathrm{s}}=3.14 \mathrm{MS} / \mathrm{m}\end{array}$ & $\begin{array}{c}2-\mu_{\mathrm{rs}}=100 \\
\sigma_{\mathrm{s}}=3.14 \mathrm{MS} / \mathrm{m}\end{array}$ & $\begin{array}{c}3-\mu_{\mathrm{rs}}=2000 \\
\sigma_{\mathrm{s}}=0 \mathrm{MS} / \mathrm{m}\end{array}$ \\
\hline Iron & 0.99 & 0.838 & 1.66 \\
\hline Aluminum & 2.185 & 1.641 & 2.404 \\
\hline
\end{tabular}

\section{CONCLUSIONS}

The proposed shielded eddy current speed sensor has sensitivity $110 \mu \mathrm{V} / \mathrm{m} / \mathrm{s}$ for iron rotating disk at $300 \mathrm{~Hz}$ and $210 \mu \mathrm{V} / \mathrm{m} / \mathrm{s}$ for aluminum rotating disk at $120 \mathrm{~Hz}$. The 3D FEM calculations shows that shielding increases sensitivity by the factor over 2 , but its main role is to suppress sensitivity to external magnetic fields and ferromagnetic objects. The linearity error is $0.26 \%$ for iron moving part at $300 \mathrm{~Hz}$.

The sensitivity can be increased several times by increasing number of turns of all coils; the limitations are the parasitic capacitances and shielding saturation.

The sensor can be optimized in terms of linearity and sensitivity using 3D FEM as the simulation results fits well with the measured values.

The sensor requires temperature compensation of the material properties and als o compensation for the changes of lift-off: using ratiometric output $\mathrm{V}_{1}-\mathrm{V}_{2} /\left(\mathrm{V}_{1}+\mathrm{V}_{2}\right)$ would be the first choice. This technique is successfully utilized in LVDT sensors. However, verification of such compensation is out of the scope of the present paper.

\section{REFERENCES}

[1] C. Moron and E. Suarez, "Non-contact digital speed sensor," Journal of Magnetism and Magnetic Materials, 133, pp. 610-612, 1994

[2] C.-T. Liu, S.-Y. Lin, Y.-Y. Yang, C.-C. Hwang, "Analytical model development of an eddy-current-based non-contacting steel plate conveyance system," Journal of Magnetism and Magnetic Materials, 320, pp. 291-295, 2008

[3] Z. Zhang, C. Xi, Y. Yan, Q. Geng, T. Shi, “A hybrid analytical model for open-circuit field calculation of multilayer interior permanent magnet machines," Journal of Magnetism and Magnetic Materials, 435, pp. 136-145, 2017

[4] P. Ripka, Magnetic Sensors and Magnetometers, Artech House, Jan 1, 2001 - Technology \& Engineering

[5] N. Takehira, and A. Tanaka, "Analysis of a perpendicular-type eddycurrent speed meter," IEE Proc. A - Phys. Science, Meas. and Instr., Manag. and Educ.- Rev. , vol. 135 , no. 2, pp. 89 - 94, Feb. 1988

[6] T. Itaya, K. Ishida, A. Tanaka, N. Takehira, and T. Miki, "Eddy current distribution for a rectangular coil arranged parallel to a moving conductor slab," IET Science, Meas. \& Tech., vol. 6, no. 2, pp. 43 - 51, Mar. 2012

[7] T. Itaya, K. Ishida, A. Tanaka, and N. Takehira, "Analysis of a forkshaped rectangular coil facing moving sheet conductors," IET Science, Meas. \& Tech. , vol. 3 , no. 4, pp. 279 - 285, Jul. 2009

[8] T. Itaya, K. Ishida, Y. Kubota, A. Tanaka, and N. Takehira, "Visualization of eddy current distributions for arbitrarily shaped coils parallel to a moving conductor slab," Progress In Electromagnetics Research M, Vol. 47, 1-12, 2016

[9] T. Itaya, K. Ishida, A. Tanaka, and N. Takehira, "Analysis of an eddy current speed meter by rectangular coil system," IEEJ Transactions on Fundamentals and Materials 133(8),416-423, January 2013

[10] T. Itaya, K. Ishida, A. Tanaka, N. Takehira, and T. Miki, "Analysis of a fork-shaped rectangular coil oriented perpendicular to moving conductor slabs,"NDT \&E International, 44, 413-420, 2011 
Final version at JMMM 502, 15 May 2020, paper\# 166568 https ://doi.org/10.1109/JSEN.2020.3000442

[11] A. Tuysuz, M. Flankl, J. W. Kolar, and A. Mutze, "Eddy-current-based contactless speed sensing of conductive surfaces," IEEE 2nd Annual Southern Power Electronics Conference (SPEC), pp. 1 - 6, Dec. 2016

[12] M. Mirzaei, P. Ripka, A. Chirtsov, and J. Vyhnanek, "Eddy current linear speed sensor," IEEE Trans. Mag., vol. 55, no. 1, pp. 1-4, 2019

[13] M. Mirzaei, P. Ripka, J. Vyhnanek, A. Chirtsov and V. Grim, "Rotational eddy current speed sensor," IEEE Trans. Mag., (Early access) 2019

[14] T. C. Wang, "Linear induction motor for high-speed ground transportation," IEEE Transactions on Industry and General Applications, vol. IGA-7, no. 5, pp. 632-642, 1971

[15] H. Sumali, E.P. Bystrom, G.W. Krutz, "A displacement sensor for nonmetallic hydraulic cylinders," IEEE Sensors Journal, vol. 3, no. 6, pp. $818-826,2003$

[16] Ansys-Maxwell software, Accessed on 20.07.2019:https://www.ansys.com/products/electronics/ansys-maxwell

[17] O.C. Coho, G.B. Kliman, J.I. Robinson, "Experimental evaluation of a high speed double sided linear induction motor," IEEE Transactions on Power Apparatus and Systems, vol. 94, no. 1, pp. 10-18, 1975

[18] M. Iwamoto, S. Sakabe, K. Kitagawa, G. Utsumi, "Experimental and theoretical study of high-speed single-sided linear induction motors," IEE Proceedings B - Electric Power Applications, vol. 128, no. 6, pp. 306-312, 1981

[19] T. Haller, W. Mischler, "A comparison of linear induction and linear synchronous motors for high speed ground transportation," IEEE Transactions on Magnetics, vol. 14, no. 5, pp. 924-926, 1978

[20] M. Iwamoto, E. Ohno, T. Itoh, Y. Shinryo, " End-Effect of High-Speed Linear Induction Motor," IEEE Transactions on Industry Applications, vol. IA-9, no. 6, pp. 632-639, 1973

[21] M. Lu, W. Zhu, L. Yin, A.J. Peyton, W. Yin and Z. Qu, "Reducing the lift-off effect on permeability measurement for magnetic plates from multifrequency induction data, " IEEE Transactions on Instrumentation and Measurement, vol. 67, no. 1, pp. $167-174,2018$

[22] M. Lu, R. Huang, W. Yin, Q. Zhao, A. Peyton, "Measurement of permeability for ferrous metallic plates using a novel lift-off compensation technique on phase signature," IEEE Sensors Journal, vol. 19, no. 17 , pp. $7440-7446,2019$ 